\title{
Jogando com a Ciência e o Curso de Informática para Inclusão Digital: Novos Olhares sobre a Ciência através do Computador
}

\author{
Playing with Science and the Course of Informatics for Digital \\ Inclusion: New Views over the Science Through Computer
}

\section{RESUMO}

Considerando-se a importância da motivação para o aprendizado de Ciências Exatas e a utilização do computador como ferramenta pedagógica, foi desenvolvido o projeto "Jogando com a Ciência", visando o contato lúdico e não formal de temas como Física, Matemática e Computação, desenvolvendo habilidades como análise sistemática de problemas e raciocínio lógico. Também foi desenvolvido o "Curso de Informática para Inclusão Digital”, com objetivo do aprendizado de informática por pessoas com pouco ou nenhum contato com computadores, através de um ensino crítico e trabalhando as necessidades e problemas da informática em seu universo. Ambos os projetos foram aplicados no Parque de Ciência e Tecnologia da USP (Cientec), sendo possível realizá-lo em outros ambientes de modo itinerante. As atividades apresentaram-se como experiências válidas de extensão universitária com o objetivo de o participante ter um contato com a ciência de uma forma lúdica e interativa, assim como de inclusão digital e social.

Palavras-chave: Ensino. Ciências. Informática.

\begin{abstract}
Considering the importance of motivation for Exact Sciences learning and the computer as a pedagogical tool, it was designed the project "Playing with Science", with the aim to have the contact and non-formal subjects such as Physics, Mathematics, and Computing and developing skills like systematic analysis of problems and logical reasoning. Also it was developed the course "Informatics for Digital Inclusion" with the goal of computer learning by people with little or no contact with computers, through a critical teaching and working Informatics' needs and problems in their universe. Both projects were implemented in the Science and Technology Park of USP (Cientec), and it is possible to do them in other environments in an itinerant way. The activities presented were a valid experience of university extension in order to the participant to have
\end{abstract}

Marta Silva Maria Mantovani e Vinícius Roggério da Rocha 
a contact with science in a fun and interactive way as well as digital and social inclusion.

Keywords: Teaching. Science. Informatics.

\title{
INTRODUÇÃO
}

\author{
"Tínhamos que enfiar todas essas coisas na cabeça para as provas, \\ gostássemos ou não. Esta coerção tinha um efeito desencorajador \\ sobre mim que, depois que passei nos exames finais, considerei \\ desagradáveis quaisquer problemas científicos durante um ano". \\ ALBERT EINSTEIN [APUD 11]
}

O ensino e a aprendizagem de ciências e de matemática no Brasil possuem sérios problemas, revelados, dentre outros indicadores, por estudo publicado pelo Programa Internacional de Avaliação de Alunos (PISA). O PISA testa a capacidade dos estudantes em leitura, matemática e ciências, e o Brasil ocupava, em 2007, as últimas posições nas três categorias: $61 \%$ dos estudantes brasileiros estavam classificados abaixo do nível dois em ciências, indicando que o estudante possui um conhecimento científico limitado que somente pode ser aplicado para explicar poucos fenômenos familiares e óbvios a partir de evidências apresentadas, ou seja, sem investigação [20]. Segundo o SARESP-2011 (Sistema de Avaliação do Rendimento Escolar do Estado de São Paulo), $58 \%$ dos alunos de Ensino Médio tiveram desempenho abaixo do básico em matemática [26]. Muitas questões apresentadas no cotidiano, como um exame anti-doping de um atleta, acidentes automobilísticos, doenças em artistas e políticos, crimes misteriosos, apresentação de grandes projetos de engenharia que causam grande impacto ao meio ambiente, tragédias naturais ou a previsão do tempo, necessitam de um conhecimento científico básico para um entendimento adequado da informação apresentada.

Mesmo observando-se a sociedade em geral, é possível observar na mídia um destaque maior para questões de pseudociência, que é a informação que se diz baseada em fatos científicos, mas que não resulta da aplicação de métodos científicos (uma discussão mais aprofundada do tema pode ser vista no texto de Knobel [14]). Matérias sobre horóscopo possuem coluna fixa na mídia impressa; classificados e anúncios sobre tarô, adivinhações e macumbas são abundantes; livros de auto-ajuda e esotéricos estão sempre nas listas de exemplares mais vendidos. Assuntos como futebol e celebridades possuem programas específicos na televisão, enquanto que a ciência é muitas vezes tratada com sensacionalismo e apenas de modo pontual ou imprecisa. Consequentemente, questões que lidam com a ciência de ponta e o desconhecido despertam medo por parte da população sem a devida informação, como no caso da abertura do Acelerador de partículas LHC (sigla em inglês para Grande Colisor de Hadrons, do CERN, a Organização Europeia para a Pesquisa Nuclear) para o qual se acreditava viável o surgimento de um buraco negro que devoraria nosso planeta [5].

Uma das formas de interpretar os fatos apresentados pela realidade é através do pensamento crítico e da discussão, buscando o entendimento da realidade apresentada. 
Essa busca deve ocorrer de forma objetiva e homogênea, estabelecendo-se procedimentos metodológicos para observação, experimentação e verificação dos fatos. Devem ser elaborados conjuntos sistemáticos de conceitos que formem teorias gerais que permitam explicar e prever os fenômenos. Para isso, a realidade deve ser organizada através da razão, que por sua vez é a capacidade intelectual para pensar e exprimir-se correta e claramente de modo a tornar a realidade compreensível por si só. Esses são pré-requisitos para uma forma de ver o mundo, conhecida como atitude científica [2].

A atitude científica é aplicável em diversas situações do cotidiano, pois fornece ferramentas para fazer boas escolhas, distinguir os argumentos sensatos dos insensatos e se posicionar frente a alguma decisão importante, reconhecer argumentos falhos ou fraudulentos nas propagandas que nos cercam, pesquisar a compra de um produto tecnológico, assim como no entendimento para sua utilização, e até mesmo na resolução de problemas dentro de uma empresa. Assim, essa é uma característica muito desejada no mercado de trabalho. Uma das ferramentas utilizadas é a lógica, que atua como uma linguagem regulada e ordenada que descreve as formas, propriedades e relações das proposições apresentadas, assim como na abstração de problemas [2]. Muitas dessas características são desenvolvidas nos cursos de ciências exatas (física, matemática, computação etc.), porém, a falta de profissionais dessas áreas no Brasil é evidente em todos os campos. No ensino, faltavam 246 mil professores formados em exatas no Ensino Fundamental II ( $6^{\circ}$ ao $9^{\circ}$ ano) e Médio em 2007 , sendo que os cursos de licenciatura contam com altos índices de evasão e os professores recebem baixa remuneração [24]. Um reflexo da deficiência do ensino de ciências exatas ocorre no mercado de trabalho, em que faltam trabalhadores nas áreas de computação, informática e tecnologia da informação e comunicação, conforme dados do Ministério da Ciência e Tecnologia (MCT) e da Coordenação de Aperfeiçoamento de Pessoal de Nível Superior (Capes) do Ministério da Educação, assim como estimativas da Associação Brasileira de Empresas de Tecnologia da Informação (Brasscom), divulgados na grande imprensa [8,12,21,27].

As características mencionadas e utilizadas na atitude científica também se fazem úteis na utilização de um computador de uma maneira mais completa, visando tirar proveito máximo de recursos em uma pesquisa na internet, por exemplo, ou também evitar determinados procedimentos que permitam a execução de programas com vírus e outros arquivos indesejados. Muitos tratam o computador como uma "caixa preta", sem ter noção de seu funcionamento, tanto da parte física quanto da sua programação, ou da importância do desenvolvimento cientifico envolvido no produto tecnológico. Assim, a utilização de programas de aprendizado em computadores tem inúmeras potencialidades a serem desenvolvidas pelos alunos, que podem ser do ensino formal, adultos acima de 60 anos, dentre outros. Isso se faz particularmente necessário quando existem laboratórios de informática em escolas e informatização de serviços no mercado de trabalho, o que exige um treinamento dos envolvidos nas atividades de uso dos computadores.

Algumas teorias definem a aprendizagem como um processo de relação do sujeito com o mundo exterior e as consequências no plano da organização interna do conhecimento, conhecida como organização cognitiva. Através da abordagem de David Ausubel [19], o sujeito atribui significados à realidade em que se encontra, constituindo pontos de partida para a atribuição de outros significados. Segundo Bruner [1], o sujeito 
tem condições de percorrer o caminho da descoberta científica através de investigação, experiências e descobertas. Mesmo em momentos em que o aluno erra, por exemplo, o professor deve reconstruir com o aluno o caminho de seu raciocínio para encontrar o momento do erro, reconduzindo-o ao raciocínio correto.

As formas de motivação utilizadas no presente projeto envolveram a abordagem crítica de criar pequenas tarefas a serem realizadas pelos alunos durante as atividades, instigando o espírito investigativo em ações não muito difíceis, o que geraria fracasso e desinteresse, nem fáceis demais, que levariam à perda de interesse; utilização de linguagem acessível e explicação de termos técnicos quando utilizados; abordagem lúdica (Jogando com a Ciência) e de crescimento profissional (Curso de Informática); apresentar as tarefas como parte de um processo no qual o aprendizado desenvolvido lhe será útil e importante.

Como metodologia do processo de ensino utilizando-se computadores, optou-se pelo ambiente educacional da oficina pedagógica, que é o ambiente destinado ao desenvolvimento das aptidões e habilidades dos alunos através de atividades laborativas orientadas por professores capacitados, onde também estão disponíveis diferentes tipos de equipamentos e materiais para o aprendizado [3]. Coloca-se o aluno em situação de aprendizagem, de modo que possa utilizar suas próprias elaborações da atividade desenvolvida, geradas de modo espontâneo, integradas aos conceitos trabalhados e que são os objetivos de ensino da atividade [6].

Assim, o desenvolvimento por parte do aluno da capacidade em entender e prever qualitativamente os fenômenos físicos é mais importante do que a simples manipulação de fórmulas ou resolução de problemas teóricos dos livros didáticos [7]. Como objetivo, os alunos devem simular o trabalho de uma comunidade científica, observando os fenômenos e investigando suas causas, assim como discutindo e comunicando suas descobertas aos outros alunos. O professor deve atuar apenas como um "regulador" externo, de modo que permita aos grupos que reconheçam suas dificuldades e progressos, reconhecendo-se na fala do professor e sendo estimulados a participarem do processo de investigação [13].

A utilização do computador no ensino revela-se extremamente positiva, dentre outros fatores, por ser um instrumento de ensino ativo, baseado na descoberta progressiva do conhecimento pelo aluno e na maior autonomia de sua aprendizagem. O computador oferece atualmente várias possibilidades de abordar Ciências de um modo interativo, dinâmico e lúdico. Entretanto, o potencial pedagógico dos computadores só poderá ser plenamente realizado se estiverem disponíveis programas educativos de qualidade e se existir uma boa articulação deles com os currículos e a prática.

A escolha do programa de computador a ser utilizado com fins educacionais deve possibilitar a aquisição e tratamento de dados (quantitativos e/ou qualitativos), simulações e alguns recursos de multimídia, tornando a atividade mais lúdica e agradável. Através desses programas, os alunos podem desenvolver um novo olhar sobre a utilização do computador e sobre o tópico visto em sala de aula. Com esse intuito, foi desenvolvido o projeto "Jogando com a Ciência", que possui diferentes atividades para trabalhar determinados conceitos de Física, Matemática e Computação, voltado para o Ensino Fundamental II e o Ensino Médio.

Dentro da visão de desmistificar o computador como sendo uma "caixa preta", popularizar o conhecimento sobre desenvolvimento tecnológico e evidenciar sua ligação 
com a ciência, assim como a inclusão social e digital, também foi desenvolvido o projeto "Curso de informática para inclusão digital”, voltado para o público geral de baixa renda e acima de 60 anos não familiarizados com a utilização de computadores. Aspectos da atitude científica podem ser trabalhados durante o ensino de informática, por ser um modo de trabalhar inerente à utilização dos computadores. Assim, o aluno deve entender os processos, e não decorar procedimentos para realizar as tarefas na máquina.

O objetivo desse trabalho foi o desenvolvimento de atividades ludo-científicas a serem desenvolvidas em computadores de modo a trabalhar questões pontuais de Física, Matemática, Computação e raciocínio lógico, assim como atividades visando à inclusão digital através de um ensino crítico e trabalhando as necessidades e problemas da informática em seu universo. Ambas as atividades deveriam ser aplicadas em grupos para testar a metodologia e a resposta dos alunos.

\section{MATERIAIS E MÉTODOS}

Os projetos foram aplicados nos anos de 2005 e 2006 no Parque de Ciência e Tecnologia da Universidade de São Paulo (Cientec). O Parque Cientec é um órgão vinculado à Pró-Reitoria de Cultura e Extensão da Universidade de São Paulo, voltado à divulgação científica que oferece entretenimento educativo e de qualidade para crianças, jovens a adultos [18]. Possui um laboratório com dez computadores, com a ideia de que fossem utilizados por uma dupla de alunos cada. A escolha de se atribuir um computador a cada par deve-se ao fato de ambos os alunos trocarem experiências mais intensamente quanto ao uso do computador e das atividades realizadas, se comparado com o uso individual da máquina.

O Parque Cientec também possui funcionários e trabalhadores terceirizados que se inscreveram para participar do curso de informática, assim como participantes do programa "Frente de Trabalho" do governo estadual de São Paulo. Constitui-se de um programa de inclusão social que tem como objetivo proporcionar ocupação, qualificação profissional e renda à população desempregada há um ano ou mais através da prestação de serviços em órgãos públicos [25].

\section{Jogando com a ciência}

O projeto envolve o desenvolvimento de experiências por meio da utilização de programas de computador com o objetivo de despertar o espírito crítico e trabalhar outros pontos característicos da atitude científica. O pesquisador deve formular uma hipótese para explicar um fato e prever outros acontecimentos decorrentes desse fato, formando assim um modelo teórico, e depois testar a hipótese através de uma experiência, para validar ou não a teoria elaborada. Esse procedimento deve ser explicado aos alunos no início de todas as oficinas, através de exemplos simples. No caso do Parque Cientec, foi utilizada uma dinâmica como exemplo, a qual consistia em adivinhar a senha que permitia o acesso aos computadores. Os atendimentos no Parque Cientec eram agendados, devendo o professor escolher a atividade com antecedência através de um folheto 
explicativo. No caso de muito movimento ou da abertura para público não agendado, poder-se-ia estabelecer uma grade horária pertinente com as atividades. O projeto é também itinerante, desde que existam computadores no ambiente onde será aplicada a oficina, haja instalação prévia dos programas a serem utilizados e uma lousa para exposição teórica, instruções e interação com os alunos.

As atividades devem seguir uma estrutura. Num primeiro momento da visitação, deve ser dada uma breve explanação sobre segurança e cuidado com os equipamentos da sala, assim como um resumo das atividades. Após essa aclimatação, inicia-se uma breve explicação teórica específica da atividade, buscando-se uma didática envolvente e descontraída, para assim começar o trabalho. Até esse ponto, os alunos não devem estar sentados em frente ao computador, pois isso desvia a atenção deles com relação ao monitor da atividade (instrutor). Para tanto, sugere-se que os alunos sentem-se voltados para o instrutor, pois esse primeiro momento deve ser breve e facilitador da interatividade dos alunos com o assunto tratado.

Quanto à utilização dos computadores, o instrutor deve estar atento a todos os alunos durante toda a atividade, seja de modo individual para ver a evolução do aluno, seja dando instruções gerais ou fazendo perguntas e comentários para os alunos. Ao final da atividade, todos devem sentar-se novamente de frente para o instrutor para discutirem conclusões sobre as experiências realizadas. A duração ideal de cada atividade é de uma hora, dependendo principalmente do engajamento da turma na atividade.

Os programas de computador escolhidos possibilitam a interatividade através da utilização de recursos gráficos com os objetivos já apresentados, sendo descritos nos itens a seguir, juntamente com a atividade desenvolvida e objetivos de cada um.

\section{a) SAM - Sistema para Análise de Movimentos}

O projeto "Análise quantitativa de movimentos: uma atividade para alunos do Ensino Médio" foi desenvolvido por professores e alunos da região de São Carlos (SP) e orientados por equipe do Centro de Divulgação Científica e Cultural (CDCC/USP), através do qual foi desenvolvido o software "Sistema para Análise de Movimentos (SAM)" com o objetivo de complementar o estudo de Física do Ensino Médio através da análise do movimento com enfoque quantitativo [17]. Pode ser baixado gratuitamente através do site do projeto*.

Através do programa SAM, é possível trabalhar vídeos e imagens com registro de movimentos e fazer sua análise quantitativa, o que envolve os conceitos de mecânica gráfica. O vídeo do movimento pode ser observado quadro a quadro, com marcações da posição do objeto e medição da distância relativa entre as marcações. Como exemplo tem-se a visualização da trajetória, através de imagens estroboscópicas, e o cálculo da velocidade de uma bola chutada em um jogo de futebol (o "tira-teima" que aparece no intervalo dos jogos transmitidos pela televisão). Os vídeos já gravados abrangem animações através das quais podem ser estudadas cinemática, mecânica e óptica/ondas, sendo possível a obtenção de novos vídeos através de gravação com câmera digital ou download da internet, com o adequado tratamento do arquivo gerado. 


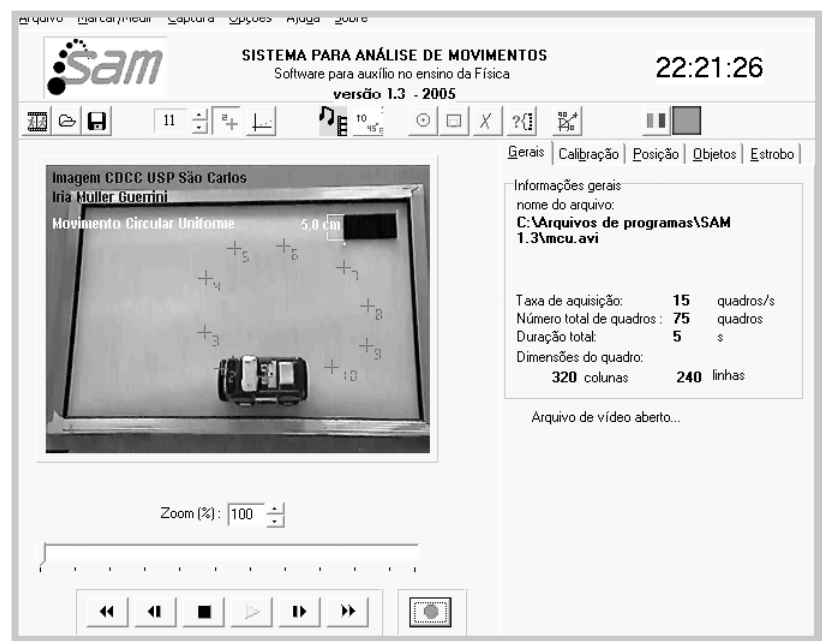

Deve ser dada uma breve explicação teórica sobre a experiência utilizada, visando retomar os conceitos dados em aula pelo professor e, assim, obter um maior rendimento da atividade. O monitor tem disponível material apropriado e desenvolvido pelos integrantes do projeto SAM para a atividade junto aos alunos. O material consiste de uma série de apostilas, versando sobre experimentos (aspectos práticos da utilização do SAM) e sobre o software SAM (sua utilização e um guia rápido).

Os alunos devem anotar os resultados obtidos na lousa, para divulgação de seus resultados perante a "comunidade científica" da sala e posterior discussão. Devem-se discutir todos os resultados, pois alguns chegarão perto dos valores da literatura ou que fazem sentido, enquanto outros podem ter tido problemas na análise que devem ser identificados e entendidos, assim como fazer uma discussão quanto à variabilidade aceitável para os valores obtidos (noções de incerteza instrumental e desvio padrão).

\section{b) Bang! Bang!}

Muito das atividades humanas estão ligadas com o momento histórico em que ocorreram. Por exemplo, os primeiros trabalhos teóricos sobre balística datam do século XVI, quando Tartaglia** estabeleceu que o ângulo de $45^{\circ}$ permitia a máxima distância de vôo e Galileu*** desenvolveu a trajetória parabólica de uma bala. Analisando-se sob óptica do materialismo dialético, esse era um dos temas necessários à expansão da classe econômica em crescimento ganhando grande interesse e financiamento [10]. A monitoria deve partir de uma breve explanação da ligação intrínseca do momento histórico sócioeconômico com o desenvolvimento da ciência, mostrando como e por que surgiu o tema estudado.

A balística estuda o movimento de projéteis, objetos que, depois de lançados por uma força inicial, movem-se sem propulsão. Quando uma bala é disparada por um revólver, ela percorre uma curva no espaço chamada trajetória. A balística é utilizada para saber o alcance da trajetória, por exemplo, que depende do tamanho, forma e massa do projétil, assim como das forças que agem sobre ele (vento, gravidade e força resultante horizontal que varia com o ângulo de lançamento).
**Apelido de Niccolò Fontana, matemático italiano (14991557), cujo nome também está ligado à solução da equação de terceiro grau.

***Galileo Galilei (1564-1642) físico, matemático, astrônomo e filósofo italiano que teve um papel preponderante na chamada revolução científica. 


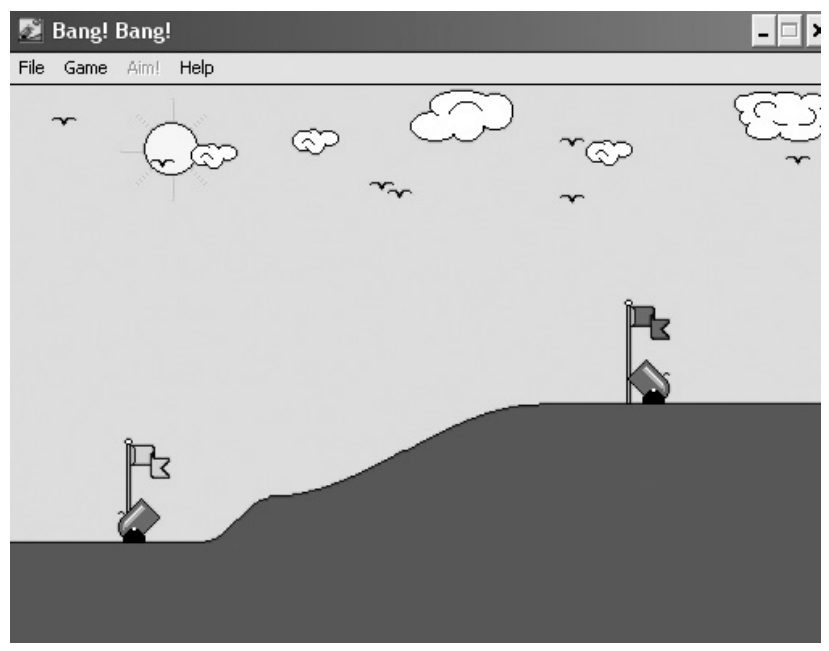

Figura 2 - Tela do programa "Bang! Bang!"

O programa “Bang! Bang!”, desenvolvido em 1990 por David B. Lutton II, simula uma batalha entre dois canhões, cada um controlado por um jogador em um mesmo computador. Para que o jogo se desenvolva, é necessário informar a velocidade de lançamento da bola do canhão, assim como seu ângulo, levando em consideração a velocidade do vento. São feitas experiências sobre a influência da velocidade do vento na trajetória do projétil, análise do movimento na vertical e horizontal (Princípio de Independência dos Movimentos) e métodos para tentar acertar o adversário. Pode-se realizar uma experiência para um único jogador, considerando o vento e na qual todos os computadores devem configurar o canhão para lançar a bola com inclinação de $90^{\circ}$ em relação ao plano horizontal. Em alguns cenários, poderá ser observada uma deflexão do movimento da bola devido à ação do vento.

Uma sugestão de experiência refere-se ao conceito de escala, com o objetivo de ter uma ideia de quanto foi reduzida à situação "real" da batalha para caber na tela de computador. Escala é a ordenação de grandezas de modo que permita a comparação. Para descobrir essa relação, a bola de canhão deve executar uma trajetória cuja distância percorrida seja prevista teoricamente. Assim, o valor descoberto em teoria será a relação entre a trajetória percorrida no mundo virtual e o mundo real. Segue o roteiro sugerido para tal experimento:

" Configure para não ter vento e escolha um cenário com altura suficiente para observar toda a trajetória de subida do projétil;

" Ajuste o canhão para velocidade inicial de $180 \mathrm{~km} / \mathrm{h}(50 \mathrm{~m} / \mathrm{s})$ e ângulo de $90^{\circ}$;

"Através da equação de Torricelli, obtém-se a distância percorrida ao longo da subida, antes de parar e começar a cair, que é de 128 metros. Caso a bola fosse jogada na Lua, adotando-se uma gravidade de 1,62 m/ $\mathrm{s}^{2}$, o projétil atingiria a altura de $772 \mathrm{~m}$.

Assim, obtém-se que o campo de batalha tem aproximadamente $530 \mathrm{~m}$ (tamanho equivalente a cinco campos de futebol). Segundo essa escala, a bola de canhão teria doze metros de diâmetro, o que não é factível com a realidade. Desse modo, pode-se 
argumentar que a bola de canhão apresenta seu tamanho na tela cem vezes maior do que na realidade para ser possível visualizar a bola em sua trajetória; ou seja, a bola de canhão, no mundo real, deve ter um diâmetro (ou calibre) de $12 \mathrm{~cm}$. Pode também ser realizada uma experiência alterando o programa para existência de vento e visualizar o que acontece com a trajetória.

Outra sugestão de experimento é o do estudo do movimento bidimensional. Durante a exposição teórica, pode-se lançar uma caneta ou giz e pedir para o aluno que o pegou desenhar na lousa a trajetória feita pelo objeto no ar durante o lançamento, por exemplo, para comentar da independência do movimento vertical, falando da ação da gravidade, e horizontal, comentando sobre a inércia. $\mathrm{O}$ aluno deve ajustar a velocidade inicial e/ ou o ângulo de inclinação do seu canhão de modo que sua bola atinja o canhão do adversário. Um método para a solução desse problema é o das “tentativas”, que envolve dar o primeiro tiro com valores arbitrários e depois ir refinando esses valores até atingir-se o alvo. Porém, um bom "chute inicial” permite chegar mais rápido à solução, ajustando os valores adequadamente a cada lançamento. Com isso, os alunos devem trabalhar a familiaridade com as grandezas para velocidade e ângulo. Para a maioria dos casos, um bom ângulo inicial é o de $45^{\circ}$ e velocidade de $180 \mathrm{~km} / \mathrm{h}$.

É uma atividade voltada para alunos do último ano do Ensino Fundamental II e Ensino Médio, de preferência que estejam em seus primeiros contatos com a Física através da cinemática. Alunos de alguns grupos que já fizeram a atividade apresentaram falta de familiaridade com os valores dos ângulos, sendo interessante uma breve revisão caso seja detectada tal necessidade.

\section{c) Programação}

O computador é uma máquina que executa ações feitas pelo ser humano. Para a tarefa ser concretizada exatamente do modo que o programador deseja, a mensagem deve ser transmitida de modo claro e sem ambiguidades através de um código que é a linguagem de programação. A aprendizagem da programação permite ao aluno entender melhor como funciona o seu computador, celular, video game e outros aparelhos eletrônicos, assim como desenvolver ideias matemáticas como estrutura lógica e recursividade (repetição de uma tarefa de modo similar ao que já foi realizado) [22].

Para exemplificar a relação "homem-máquina" durante a monitoria, pode ser realizada uma breve dinâmica na qual o monitor representa o computador e o quadro negro, o teclado, através do qual o aluno escreve as instruções. É definida uma tarefa simples, como, por exemplo, jogar uma bolinha de papel no cesto de lixo. Porém, a instrução é escrita pelo aluno incompletamente apenas como "jogar a bola" e não foi dito para o "computador" pegar a bolinha nem onde ela deveria ser jogada.

O "Logo" é uma linguagem de programação relativamente fácil e simples, podendo ser baixado gratuitamente do site do Núcleo de Informática Aplicada à Educação (NIED) da UNICAMP**** ou do programa Educ@r r**** do CDCC/USP.O ambiente tradicional possui uma "tartaruga gráfica" que simboliza na tela o robô que receberá os comandos do usuário. Com ela é possível fazer desenhos, contas e simulações gráficas. É possível, por exemplo, simular os movimentos estudados na Física [17], entendendo

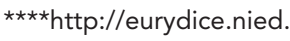
unicamp.br/softwares/ software_detalhes. php?id=33zzzzzdownload $=1$ 


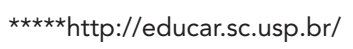
fisica/logo/logo.html melhor os conceitos desses movimentos sob outra óptica, ou mesmo dar instruções ao programa para fazer desenhos, e assim aprender os fundamentos da programação de computadores. Se a tartaruga executa funções na tela diferentes das idealizadas pelo aluno, isso faz com que o aluno reflita sobre os comandos que ele passou ao programa e tente encontrar uma solução para esse problema. Existem também comandos específicos que permitem comandar um robô físico e desenvolver um projeto de robótica.

Visando criar uma familiaridade com o programa, a primeira atividade realizada é a de usar a tartaruga para desenhar na tela. Pode-se desenhar um quadrado através de comandos que mandem a tartaruga andar um determinado número de passos desenhando uma linha em uma determinada direção, depois outro comando que a faça virar $90^{\circ}$ à direita e andar o mesmo número de passos. Repete-se esse comando quatro vezes até formar um quadrado, e depois é mostrado um comando que envolve a repetição dos comandos durante um número determinado de vezes. Após essa etapa, podem ser realizados outros desenhos, inclusive fazendo a tartaruga andar sem desenhar.

Outra atividade envolve a programação da tartaruga para simular um movimento retilíneo uniforme, servindo como uma ideia de como são programados os jogos de computador. Para tanto, o algoritmo deve ser discutido pelo monitor antes de os alunos realizarem as primeiras tentativas. Para simular o movimento da tartaruga andando para a direita e realizando marcações a cada deslocamento constante de passos, faz-se necessária uma sub-rotina, que é uma sequência de instruções feita em separado e utilizada pelo programa a ser construído. Basicamente, o programa limpa a tela, diz o tamanho da ponta da caneta e a posição inicial da tartaruga e aplica a sub-rotina, a qual realiza as seguintes funções:

" Coloca a tartaruga na posição desejada;

" Desce a caneta;

" Faz a tartaruga andar para fazer um ponto;

"Sobe a caneta;

"Define-se o valor do novo ponto, após um deslocamento constante de passos;

" A tartaruga anda até o ponto definido.

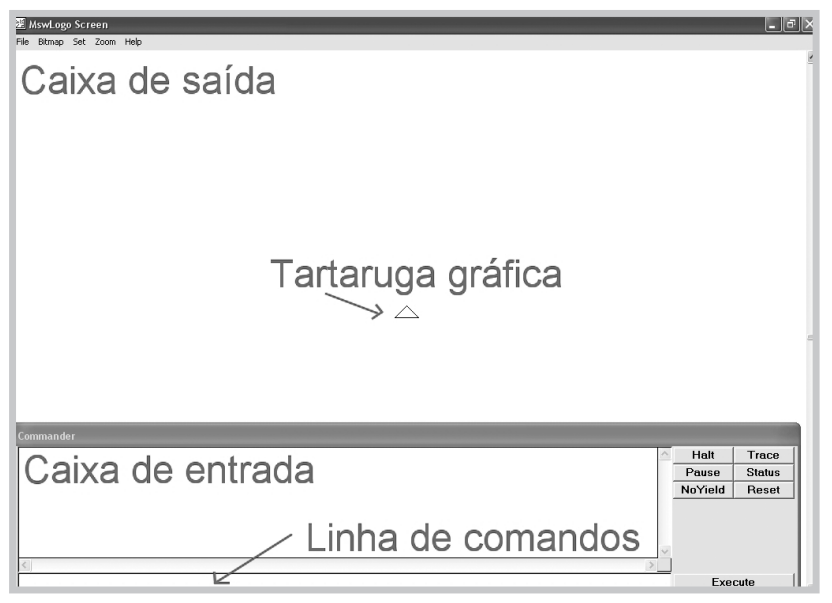

Figura 3 - Tela do

"SuperLogo", um dos programas para trabalhar com a linguagem Logo 
Uma sugestão de sintaxe para esse algoritmo pode ser vista no site de Mecânica Gráfica do Projeto Educ@r. Essa atividade é voltada para alunos do Ensino Médio.

\section{d) Matemática}

A resolução de problemas envolve diversos caminhos, com alguns deles podendo resultar em nenhum avanço. Alguns meios de se resolver o problema são mais rápidos que outros, mas dependem de um conhecimento maior de todas as relações que envolvem o problema ou mesmo de uma visão mais ampla que de costume. Durante a oficina, o aluno deve movimentar um peão através de um labirinto, sendo que o número de casas a serem avançadas é obtido através dos dados. A autorização para movimentar ou regredir no labirinto depende do cálculo correto da expressão matemática proposta. No início são contas simples com as quatro operações fundamentais da aritmética, que vão se tornando mais complexas com o decorrer do jogo. Com isso, é oportuno e interessante o trabalho de conceitos como notação científica, números negativos, potenciação, sentenças matemáticas e dimensões.

O programa utilizado é o "Trilha Matemática”, produzido pelo projeto "Construção de Software para o Auxílio no Ensino de Matemática Fundamental” (COSAEMAF) da Universidade Regional Integrada do Alto Uruguai e das Missões (URI) [15]. Pode ser jogado em rede, sendo que cada computador é representado por um peão e os alunos sentem-se motivados a interagirem com alunos dos outros computadores através da atividade desenvolvida. Quanto mais rápido forem realizadas as contas, mais rapidamente pode-se chegar ao fim do labirinto. Se errar, o aluno recebe uma penalidade equivalente a um avanço a menos da próxima vez que jogar os dados, evitando-se que o jogador somente responda as questões fáceis. $\mathrm{O}$ aluno também deve estar atento ao caminho que percorre no labirinto, exercitando também a capacidade de concentração em múltiplas tarefas. O programa permite a escolha do número de termos (dois, três ou quatro) da expressão e as operações desejadas (adição, subtração, multiplicação, divisão e potenciação, com expoente máximo igual a dois ou três), havendo a opção ainda de ter ou não números negativos envolvidos.

Existem duas versões do programa: em uma, o labirinto é visto de cima, somente em duas dimensões, enquanto na outra, o tabuleiro é percorrido por um boneco controlado

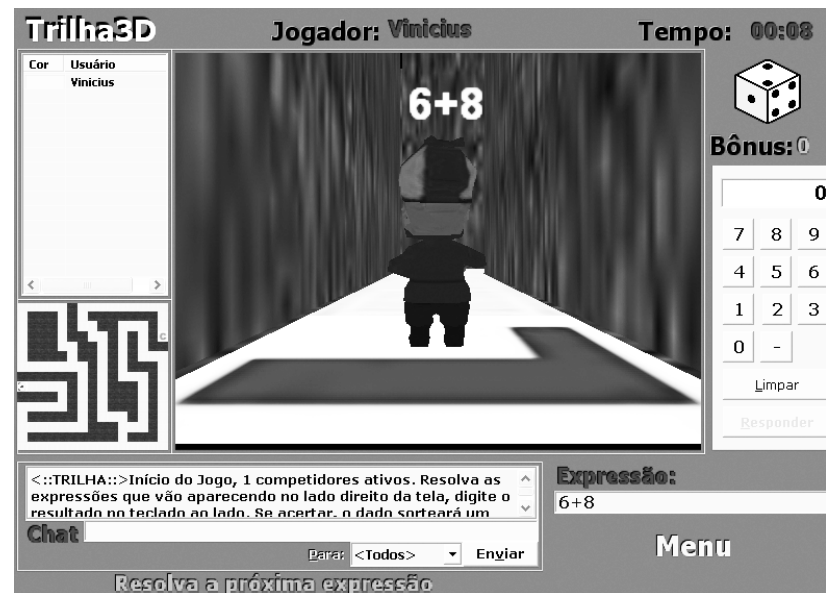

Figura 4 - Tela do programa "Trilha 3D" 
em primeira pessoa, em um labirinto tridimensional. Como atividade, os alunos devem, inicialmente, ambientar-se com o jogo $2 \mathrm{D}$ e fazer uma breve revisão de como realizar as operações de aritmética, e depois partir para o jogo $3 \mathrm{D}$, com uma breve explicação do que é $3 \mathrm{D}$ e discussão dos problemas encontrados na primeira atividade. Algo que também pode ser comentado diz respeito ao fato de alguns não olharem o mapa que têm à disposição no programa e seguirem pelo caminho errado. Na resolução de exercícios, acontece de muitos alunos mal lerem o enunciado e saírem fazendo contas, sem pensar.

Essa atividade é voltada para os primeiros anos do Ensino Fundamental II, onde são dados os conteúdos de potência e números negativos, mas podem ser utilizados por outros alunos que desejem trabalhar a destreza em contas aritméticas simples.

\section{e) llusões de Óptica}

Certas imagens parecem "enganar” o sistema visual parecendo ser o que não são, sendo denominadas "ilusões de óptica". Algumas são explicadas em termos fisiológicos ou cognitivos. O cérebro busca extrair informações constantes de modo a classificar tudo aquilo de que toma consciência, tornando a percepção de mundo em parte previamente formada [9]. Por exemplo, ao observar-se duas retas paralelas idênticas (Figura 5a), mas uma delas com duas retas em ângulo agudo em cada ponta e outra com retas iguais, porém com ângulos obtusos, tem-se a impressão de que a reta cujas extremidades possuem semirretas em ângulo obtuso é maior do que a outra. Ou também se essas linhas paralelas fossem colocadas entre duas linhas que se fecham como em perspectiva (Figura $5 \mathrm{~b}$ ), parecendo que uma linha está mais curta que a outra. $O$ nosso cérebro tende a obter conclusões sobre o tamanho como se os comparasse com os dormentes de um trilho de trem realmente em perspectiva do mundo tridimensional em que vivemos.

Inúmeros outros exemplos de ilusões de óptica podem ser dados, inclusive gerando a ilusão de movimento ou utilizados em obras como as do artista holandês M. C. Escher [16]. Porém, certos fenômenos ópticos também parecem enganar nosso sistema visual, mas não são ilusões porque existem de fato como fenômenos explicados pela Física. Um exemplo são os sistemas de óculos $3 \mathrm{D}$, onde são feitas duas imagens ligeiramente deslocadas e sobrepostas, mas uma delas somente é percebida pelo olho esquerdo e outra pelo olho direito, simulando, assim, a visão estereoscópica do ser humano e dando a noção de profundidade.

O cientista deve observar a natureza de diferentes formas, buscando uma explicação para o que percebe. Porém, muitas pessoas não possuem o hábito de observar com a devida atenção, que é uma arte contrária à falta de tempo cotidiana da sociedade contemporânea. Desse modo, também é oportuno a apresentação de imagens com objetos ocultos, exigindo maior atenção do observador para encontrá-los.

A atividade elaborada consiste de uma apresentação interativa com diversos exemplos e explicações de fenômenos ópticos e ilusões de óptica. Com isso, diferentes fenômenos físicos e de percepção são apresentados e explicados, como uma forma da união entre ciência e arte. A atividade pode ser utilizada por qualquer público, sendo bastante autoinstrutiva. Porém, alguns objetos, como papel celofane verde, vermelho e azul e espelhos, são necessários para melhor aproveitamento da atividade. 




Figura 5 - Exemplos de

ilusão de óptica

\section{f) Estratégia}

Jogos de estratégia também são ferramentas muito úteis no desenvolvimento de diversas habilidades, como o raciocínio lógico, estratégico e matemático. Ao jogar, o jovem tem a oportunidade de lidar com suas pulsões, frustrações e desafios, ganhando confiança e aprendendo a analisar sistematicamente os problemas, expor ideias, conclusões e soluções, avaliar antecipadamente as vantagens e inconvenientes de uma decisão, controlar a impulsividade e responsabilizar-se por seus atos, tornando a atividade lúdica um laboratório com experiências reflexivas movidas pela curiosidade e que geram conhecimento, assim como na ciência [4].

Um dos clássicos exemplos de jogos de estratégia é o xadrez, mas existem outros exemplos. Um deles é o Dominate, desenvolvido por Ken Foster e Sam M. Misemer em 1993, onde o aluno deve expandir o número de peças da sua cor no tabuleiro, visando terminar o jogo com o maior número em relação ao adversário. Eventualmente ocorrem disputas por certos pontos do tabuleiro, o que exige uma estratégia de ação e de resposta aos ataques do adversário. Outro exemplo é o Klotski, desenvolvido pela ZH Computer Corp. em 1991. É um jogo onde o objetivo é passar um bloco vermelho entre outras peças amarelas, só que tendo o espaço para movimentação muito restrito. Para resolver o problema, o aluno deverá desenvolver um algoritmo e sua capacidade de elaborar etapas para a resolução de um problema complexo.

Outra abordagem possível para esse tipo de atividade é fazer com que os alunos descubram as regras do jogo e as escrevam no quadro para os colegas, como se estivessem pesquisando as regras de funcionamento da natureza e comunicando suas descobertas para os outros pesquisadores. Existem inúmeros exemplos de jogos que podem ser utilizados no desenvolvimento de habilidades utilizadas em ciências exatas.

\section{Curso de informática para inclusão digital}

A Ciência permite o desenvolvimento de diversos produtos tecnológicos, como os computadores e os programas utilizados nesse trabalho. Porém, existem muitos alunos e pessoas de diferentes faixas etárias que possuem pouco ou nenhum contato com um computador, mesmo em uma sociedade onde o uso da informática ocorre de modo cada vez mais amplo. Para essas pessoas conseguirem se beneficiar ao máximo dos frutos 
desse desenvolvimento é necessário realizar uma inclusão digital junto a esse público. Com esse objetivo, foi desenvolvido um curso de informática.

O projeto "curso de informática para inclusão digital" inclui aulas de como utilizar programas com um sistema operacional, processadores de texto, planilhas eletrônicas, navegadores de internet e correio eletrônico. Porém, não são ensinadas receitas prontas para realizar as tarefas. Ao contrário, realiza-se uma abordagem na qual o aluno deve intuir o que deve ser feito a partir de uma comparação com o mundo real. Por exemplo, compara-se o sistema de arquivo de um computador, com pastas e subpastas, ao esquema físico de pastas que já existem há gerações. Uma folha de papel é comparada ao arquivo que será alterado e salvo em uma pasta do computador.

Logo na primeira aula, um computador é aberto para mostrar os componentes e seus periféricos, com o objetivo de criar uma visualização da tecnologia existente, identificar os componentes periféricos do cotidiano e desmistificar o conteúdo de um computador, pois faz-se necessário também um ensino da tecnologia [14]. Também na aula inaugural devem ser discutidos com os alunos os objetivos e expectativas que possam ter quanto ao curso e sobre o papel e a utilização da informática nos dias de hoje, visando construir uma crítica quanto à utilização do computador.

Também é necessária, nas primeiras aulas, uma atenção especial ao modo como o aluno usa o mouse e o teclado, já que muitos alunos podem nunca ter utilizado um computador, e assim otimizar seu uso sem gerar vícios de utilização e problemas musculares nas mãos e braços. A utilização de editores de imagem que permitam desenhar com o mouse e de processadores simples de texto podem melhorar a intimidade do aluno com o manuseio desses periféricos.

São realizadas dez aulas, com duração mínima de uma hora cada, com os seguintes temas: introdução à computação (hardware e periféricos, software e principais programas), processadores de texto, planilhas eletrônicas, gerenciador de banco de dados, impressão, apresentação, internet, (conexão e navegadores), correio eletrônico. Como motivação de atividade, os alunos devem elaborar seu currículo ao longo do curso, o que envolve tarefas como ligar e desligar um computador, acessar o seu perfil de usuário, utilizar um sistema operacional, abrir, transformar e salvar um documento, utilizar um processador de texto e suas potencialidades na edição de seu texto, imprimir um documento, utilizar um navegador de internet para realizar buscas, ver notícias e oportunidades de emprego, assim como utilizar um correio eletrônico para enviar o currículo. Também foram apresentadas atividades do projeto "Jogando com a Ciência", promovendo um aspecto mais lúdico ao aprendizado de informática. Através dessas atividades, o aluno desenvolve seu contato com o computador e prepara um resumo de seu perfil profissional, trabalhando sua inclusão digital juntamente com sua reinclusão no mercado de trabalho.

Com relação à internet, são trabalhados temas como a melhor utilização de ferramentas de busca, que são de extrema importância, mas que causam muita confusão por parte dos iniciantes em informática para encontrar o que desejam frente ao grande número de resultados da busca. Outro tema a ser tratado diz respeito aos vírus, spams e segurança na internet, explicando as situações mais comuns onde esses problemas podem ser encontrados no cotidiano do usuário e seus efeitos sobre o computador. 


\section{DISCUSSÃO E CONCLUSÃO}

\section{Jogando com a Ciência}

Entre novembro de 2005 e novembro de 2006, 660 jovens participaram do projeto em diferentes turmas e em todas as atividades descritas, sendo as atividades "Matemática", "Bang! Bang!" e "Ilusões de Óptica” as mais aplicadas. A maioria dos alunos pertencia às séries iniciais do Ensino Fundamental II da rede pública de ensino. Foram produzidos relatórios a cada atividade realizada, constando o nome do monitor responsável, data, horário de início e término da atividade, nome da escola, série, número de alunos e professor responsável, assim como a descrição da atividade realizada e a resposta dos alunos com relação ao comprometimento à atividade. Foram feitas pequenas adequações a cada monitoria com base nesses relatórios, visando à obtenção de atividades que fossem ao mesmo tempo padronizadas pela qualidade e maleáveis o suficiente para se adaptarem a diferentes grupos de alunos, apresentadas nesse trabalho.

Os alunos que participaram da atividade "SAM" realizaram a experiência sobre queda livre, com o objetivo de calcular a aceleração da gravidade. Os cálculos foram realizados em folhas de papel e os valores colocados na lousa, resultando na obtenção de dados compatíveis com o valor da gravidade conhecida. Foi realizada discussão sobre a incerteza em medidas experimentais, conversão de unidades (pois a resposta era obtida $\mathrm{em} \mathrm{cm} / \mathrm{s}^{2}$ ) e força da gravidade, principalmente.

Com relação à atividade "Bang! Bang!", os alunos participaram respondendo simples perguntas realizadas durante breves exposições teóricas (como, por exemplo, o movimento que uma caneta faz no ar ao ser lançada e o princípio da independência dos movimentos). Utilizaram o programa com as experiências sugeridas, sempre com momentos para descreverem o resultado obtido para a turma. Segue a narração de uma experiência realizada para perceber a influência do vento no movimento dos corpos, que consta do relatório de atividades do projeto:

Foi pedido para os alunos mudarem a configuração do jogo para um jogador e tirarem o vento, depois jogarem a bola $90^{\circ}$ para cima com uma velocidade de $180 \mathrm{~km} / \mathrm{h}$. Viram que ela caía logo à frente do canhão. Depois, foi pedido a todos que alterassem a configuração para ter vento e gerarem novos jogos até conseguirem uma velocidade do vento acima de $50 \mathrm{~km} / \mathrm{h}$. Ao que o primeiro grupo conseguiu tal feito, foi pedido a todos que parassem suas atividades e olhassem para o computador daquela dupla. Foi alterada a velocidade para valores muito baixos e muito altos para notarem a influência do vento e sua relação com a velocidade da bola.

Também realizaram tentativas de destruir o canhão inimigo, e o aluno da dupla que tivesse melhor noção de quais fatores (velocidade e ângulo) deveria alterar, assim como sua intensidade, conseguiria abater o canhão do adversário.

A atividade "Programação" apresentou uma resposta positiva dos alunos ao perceberem que estavam dando instruções a um robô, e foi feito um paralelo com o que ocorre em um computador.

A atividade "Matemática" envolvia breves explicações sobre números negativos, 
envolvendo analogias com “dever dinheiro a alguém”, potências e operações aritméticas. O caráter lúdico do jogo e o desafio entre duplas transformaram a atividade em emocionantes disputas para terminar de modo rápido e correto as expressões matemáticas.

Através da atividade "Ilusões de Óptica", os alunos puderam interagir com a apresentação desenvolvida, escolhendo as figuras e animações, e com os colegas, comentando sobre o observado. Despertou-se a curiosidade para entenderem como ocorriam os fenômenos observados, o que podia ser explicado através da própria apresentação ou do monitor da atividade.

O jogo Dominate, da atividade "Estratégia”, foi aplicado juntamente com outras atividades descritas, por demandar um tempo menor de execução. De modo geral, os alunos apresentaram dificuldade inicial para entender as regras do jogo, perdendo algumas rodadas seguidas, mas com o tempo e observação conseguiam desvendar o regulamento.

Em aplicações futuras desse projeto, sugere-se empregar as mesmas atividades para mais turmas e em outras instituições, assim como o desenvolvimento de mais atividades utilizando-se outros programas de computador.

\section{Curso de informática para inclusão digital}

Inscreveram-se 28 pessoas, dentre funcionários do Parque Cientec, terceirizados e Frente de Trabalho, para o curso, ministrado em janeiro e fevereiro de 2006. Porém, apenas cinco pessoas o frequentaram, sendo que os que não participaram alegaram problemas com o horário do curso, oferecido após o horário de expediente, e falta de tempo, pois precisavam cuidar da família. Apesar do baixo número de alunos, o aprendizado foi muito proveitoso aos alunos, consolidando-se como uma importante experiência profissional e de vida. Tiveram um contato mais formal com programas muito utilizados em diversas atividades pessoais e profissionais, possibilitando um melhor aproveitamento e maior intrepidez para continuar aprendendo mais sobre informática e tecnologia por conta própria.

Por conta do baixo número de alunos, essa atividade foi considerada uma experiência da aplicação da metodologia para futuras turmas, inclusive em outros contextos sociais. Para as aulas inaugurais, pode ser utilizado um programa específico para principiantes em informática da terceira idade desenvolvido por um grupo de alunos da Fundação Nokia* [23], através do qual boa parte das dificuldades apresentadas pelos alunos é trabalhada, como não enxergar bem a tela e a utilização do mouse.

\section{REFERÊNCIAS BIBLIOGRÁFICAS}

[1] BRUNER, Jerome. O Processo da Educação. Lisboa: Nova Biblioteca 70, 1995.

[2] CHAUÍ, Marilena. Convite à Filosofia. 12 ed. São Paulo: Ed. Ática, 1999.

[3] DA SILVA, A parecida F.; KODAMA, Helia M. Y. Jogos no Ensino da Matemática. In: Bienal da Sociedade Brasileira de Matemática. Salvador: 2004. Disponível em: www.bienasbm.ufba.br/OF11.pdf. Acesso em: 28 abr. 2010.

[4] DA SILVA, Rosineida A. Oficina Pedagógica: necessidades e objeto da atividade em contradição. Dissertação de mestrado, São Paulo: Pontifícia Universidade 
Católica de São Paulo, 2006.

[5] EFE - Agência EFE. Indiana se suicida com medo de experimento no LHC. Portal Terra Notícias, 10 set. 2008. Disponível em: http://noticias.terra.com. $\mathrm{br} /$ mundo/interna/oOI3172186-EI8143,oo-Indiana+se+suicida+com + medo $+\mathrm{d}$ e+experimento+no+LHC.html. Acesso em: 28 abr. 2010.

[6] FERREIRO, Emília. Reflexões sobre alfabetização. São Paulo: Editora Cortez, 1996.

[7] FIOLHAIS, Carlos; TRINDADE, Jorge. Física no computador: o computador como uma ferramenta no ensino e na aprendizagem das ciências físicas. Rev. Bras. Ensino Fís., v. 25, n. 3, Set. 2003. Disponível em: http://www.scielo.br/ scielo.php?script $=$ sci_arttext\&pid $=S 1806-11172003000300002 \& \operatorname{lng}=e n \& n r m=i$ so. Acesso em: 28 abr. 2010.

[8] FREITAS, João Paulo. Setor de TIC tem déficit de profissionais. Gazeta Mercantil, 5 mai. 2009.

[9] GREGORY, Richard L. Knowledge in perception and illusion. Phil. Trans. R. Soc. Lond. B 352, pp. 1121-1128, 1997.

[10] HESSEN, Boris. As raízes sociais e econômicas do 'Principia' de Newton. Trad. João Zanetic e Maria Regina D. Kawamura, Revista de Ensino de Física, v. 6, n. 1, abr. 1984. Original: The social and economic roots of Newton's 'Principia'. In: BUKHARIN, N. I. et al. Science at the cross roads. Frank Crass; Co. Ltd, pp. 147-212, 1972.

[11] HOLLINGDALE, Stuart. Makers of Mathematics. New York: Penguin Books, 1989.

[12] IDG NOW. Mercado brasileiro de TI crescerá três vezes mais que mundial, diz MCT. 20 dez. 2007. Disponível em: http://idgnow.uol.com.br/mercado/2007/12/20/idgnoticia.2007-12-20.7791001767/. Acesso em: 28 abr. 2010.

[13] JÚLIO, Josimeire; VAZ, Arnaldo. Grupos de alunos como Grupos de Trabalho: um estudo sobre atividades de investigação. Revista Brasileira de Pesquisa em Educação em Ciências, v. 7, n. 2, 2007.

[14] KNOBEL, Marcelo. Ciência e Pseudociência. Física na Escola, v. 9, n. 1, 2008.

[15] LISE, Douglas M.; BRANCHER, Jaques D. Trilha Matemática - Um jogo multiusuário para despertar o interesse em jogos didáticos de computador. In: Congresso Iberoamericano de Informática Educativa, 7, Monterrey: 2004.

[16] LOCHER, J. L. Magic of M. C. Escher. New York: Thames; Hudson, 2006.

[17] MAGALHÃES, Mônica G. M.; SCHIEL, Dietrich; GUERRINI, Iria M.; MAREGA Jr., Euclydes. Utilizando tecnologia computacional na análise quantitativa de movimentos: Uma atividade para alunos do Ensino Médio. Revista Brasileira de Ensino de Física, vol. 24, n. 2, jun. 2002. Disponível em: http://www.scielo. br/scielo.php?script=sci_arttext\&pid=S1806-11172002000200004\&lng=en\&nr $\mathrm{m}=$ iso. Acesso em: 29 abr. 2010.

[18] MANTOVANI, Marta S. M.; MASSAMBANI, Oswaldo. Ciência e Tecnologia no Parque. São Paulo: Edusp, 2004.

[19] MOREIRA, M. A.; MASINI, E. F. S. Aprendizagem significativa: a teoria de David Ausubel. São Paulo: Moraes, 1982.

[20] OECD, 2007 Executive Summary.PISA2006: Sciences Competencies for Tomorrow's World. Disponível em: http://www.pisa.oecd.org/dataoecd/15/13/39725224.pdf. Acesso em: 28 abr. 2010. 
[21] OLIVEIRA, Celso Henrique Pedroso de. Sobram vagas, mas faltam profissionais habilitados na área de informática. Canal Rh, 19 out. 2006.

[22] PAPERT, S. LOGO: Computadores e Educação. Trad. J. A. Valente et al., São Paulo: Brasiliense, 1980.

[23] RODRIGUES, Jade C. S.; GOMES, Ludymila L. A.; DOS SANTOS, Marden E. Descomplicando a tecnologia-software de auxílio aos idosos. In: Feira Brasileira de Ciências e Engenharia (FEBRACE), 8. São Paulo: 2010. Disponível em: http://febrace.org.br/virtual/SOC/73/. Acesso em: 28 abr. 2010.

[24] RUIZ, Antonio I.; RAMOS, Mozart N.; HINGEL, Murílio. Escassez de professores no Ensino Médio: Propostas estruturais e emergenciais. Brasília: $\mathrm{CNE} / \mathrm{CEB}$ (Conselho Nacional de Educação/Câmara de Educação Básica), 2007. Disponível em: http://portal.mec.gov.br/cne/ arquivos/pdf/escassez1.pdf. Acesso em: 28 abr. 2010.

[25] SÃO PAULO (Estado). Cidadão.SP - Portal de Serviços do Governo do Estado de São Paulo. Disponível em: http://www.empresa.sp.gov.br/servico. php?serv=303458. Acesso em: 3 maio 2010.

[26] SÃO PAULO (Estado). Saresp 2011. Disponível em: http://saresp.fde.sp.gov. br/2011/\#. Acesso em: 7 mar. 2012.

[27] TURCI, Fabio. Profissões na área de exatas estão entre as mais requisitadas no Brasil. Jornal da Globo, 9 fev. 2011. Disponível em: http://g1.globo.com/jornal-da-globo/noticia/2011/o2/profissoes-na-area-de-exatas-estao-entre-mais-requisitadas-no-brasil.html. Acesso em: 20 jun. 2012.

\section{AGRADECIMENTOS}

Os autores agradecem à bolsa-estágio fornecida pela Coordenadoria de Administração Geral da USP (CODAGE) através da Pró-Reitoria de Cultura e Extensão Universitária. Agradecemos também à professora Iria Muller Guerrini pelo treinamento no programa SAM, aos estagiários e funcionários do Parque Cientec, em especial Alexandre de Arruda Postigo, pela divulgação do projeto através do Boletim Informativo do Parque (“O Bugio"), Marcos Rondinelli Araújo, pela manutenção nos computadores, Luciane Nogueira Amaral dos Santos, pela divulgação das atividades desse trabalho junto às escolas para agendamento, e Fabrício Luis de Lima Silva, pela ideia do curso de informática e suporte na manutenção da sala de computadores.

MARTA SILVA MARIA MANTOVANI professora titular do Instituto de Astronomia, Geofísica e Ciências Atmosférica da USP (IAG-USP) e ex-diretora do Parque de Ciência e Tecnologia da Pró-Reitoria de Cultura e Extensão Universitária da USP - e-mail: msmmanto@usp.br

VINícIUS ROGGÉRIO DA ROCHA Instituto de Astronomia, Geofísica e Ciências Atmosféricas da Universidade de São Paulo (IAG/USP) - Rua Tubarana, 75 - Vila Mariana - CEP 04113o-ozo - São Paulo-SP - e-mail: viniroger@yahoo.com.br. 